\title{
石墨炔：从合成到应用
}

刘鸣华1，李玉良 ${ }^{2}$

1国家纳米科学中心, 北京 100190

2 中国科学院化学研究所, 北京 100190

\section{Graphdiyne: from Synthesis to Application}

\author{
LIU Minghua ${ }^{1}$, LI Yuliang 2,* \\ ${ }^{1}$ National Center for Nanoscience and Technology, Beijing 100190, P. R. China. \\ ${ }^{2}$ Institute of Chemistry, Chinese Academy of Sciences, Beijing 100190, P. R. China. \\ Email: liuminghua@nanoctr.cn (L.M.); lily@iccas.ac.cn (L.Y.).
}

石墨炔是一种新型碳的同素异形体, 是由 $s p$ 和 $s p^{2}$ 两种杂化形式的碳原子组成的二维层状材 料 1 。具有中国自主知识产权的石墨炔自 2010 年 被首次成功合成以来, 吸引了全世界来自化学、物 理、材料、生物和电子等学科的科学家对其进行探 索 ${ }^{2}$ 。石墨炔独特的纳米级孔隙、二维层状共轭骨 架结构及半导体性质等特性, 使之在能源、电化 学、光催化、光学、电子学等诸多领域优势显著 ${ }^{3}$ 。 石墨炔的基础和应用研究已取得了重要成果, 并 迅速形成了一个新领域。本专辑中收集了我国部 分科学家在相关领域的研究成果, 文章将展示石 墨炔的理论研究, 实验合成、修饰、结构表征、性 质研究与应用方面的最新进展。

帅志刚等 ${ }^{4}$ 对石墨炔, 以及锡烯等层状体系的 电子结构、形变势、电声耦合和电荷输运性质进行 了回顾。指出具有独特电子结构和高迁移率的石 墨炔能成为继石墨烯之后未来的纳米电子器件材 料。此外他们还分析了形变势方法对石墨烯和石 墨炔等二维材料研究的适用性。张胜利等 5 使用第 一性原理计算研究了单层石墨炔的纳米带电子输 运性质和及石墨炔对小分子的吸附。从能带、载流 子浓度等方面全面探讨了 Sc、Ti 掺杂石墨炔对甲 醛分子 $(\mathrm{HCHO})$ 的响应。研究了石墨炔与氨基酸分 子间相互作用, 研究了吸附氨基酸对石墨炔电子 输运的影响, 探讨石墨炔在生物传感方面的潜在 应用。

张锦等 6 总结了石墨炔合成方法的研究进展, 包括有机全合成、表面在位化学反应和溶液相聚
合反应等几个方面。石墨炔中炔键单元的高活性 为其化学修饰与掺杂提供了良好的平台, 李玉良 等 7 介绍了石墨炔的非金属杂原子掺杂、金属原子 修饰以及表面改性, 并深入探讨掺杂与衍生化对 石墨炔材料的电子性质的影响及其对光电化学催 化性能的协同增强。崔晓莉等 ${ }^{8}$ 以碳化钙和三溴苯 为原料, 通过机械化学方法合成了氢取代石墨单 炔, 发现其为 $p$ 型半导体, 带隙为 $2.30 \mathrm{eV}$, 在催 化产氧和光催化方面具有应用潜力。

石墨炔结构的表征, 对于指导石墨炔合成, 探 索石墨炔结构与其物理化学性能之间的构效关系 等方面都具有非常重要的意义。鲁统部等 ${ }^{9}$ 总结了 表征石墨双炔形貌、厚度、晶体结构以及碳的成键 形式的方法。

王丹等 10 基于石墨炔的电子转移增强特性, 概述了石墨炔及其电子转移增强特性的新研究进 展, 包括金属氧化物/石墨炔、金属纳米颗粒/石墨 炔、聚合物/石墨炔以及染料分子/石墨炔等多种石 墨炔基材料。文章从理论和实验研究两个方面详 细阐述了石墨炔的电子转移增强特性、石墨炔与 不同材料的相互作用以及相关的应用。而王吉政 等 ${ }^{11}$ 通过石墨炔修饰, 大幅提高了 $\mathrm{ZnO}$ 紫外探测 器的性能, 并发现石墨炔修饰的 $\mathrm{ZnO}$ 探测器性能 的提高归因于石墨炔良好的空穴传输特性。

石墨炔宽的层间距、大的比表面积、独特的三 维孔隙结构和好的导电性使其在能源存储器件电 极材料应用中具有巨大的潜力。黄长水等 12 详细 介绍了近年来石墨炔在储能方面的理论分析和实 
验进展。石墨炔作为电极材料在储钠储锂方面的 容量与理论值相近。此外石墨炔作为电极材料成 功应用于超级电容器和金属-硫电池, 并表现出了 优异的容量存储性能。石墨炔纳米形貌的调控、石 墨炔的热处理, 以及异原子的掺杂等均可以有效 地提高石墨炔在这些储能器件中的性能。而刘辉 彪等 13 发展了基于超分子化学的新方法对石墨炔 进行原位氮掺杂, 通过利用石墨炔与有机共轭分 子间强的 $\pi-\pi$ 作用, 原位制备了石墨炔/卟吩复合 材料薄膜, 为可控制备掺氮石墨炔复合材料提供 了新的思路。

石墨炔自成功合成以来引起了研究者极大的 兴趣和关注。目前为止, 石墨炔的基础和应用研究 方兴未艾, 显示了巨大广阔的空间。石墨炔的可控 制备方法、系统表征方法、可控结构等仍然需要不 断去探索。另外, 石墨炔在电子、能源、催化、信 息技术等方面的研究在未来五年将展示无限的创 新空间。

\section{References}

(1) Li, Y. J.; Xu, L.; Liu, H. B.; Li, Y. L. Chem. Soc. Rev. 2014, 43, 2572. doi: $10.1039 / \mathrm{C} 3 \mathrm{CS} 60388 \mathrm{~A}$

(2) Li, G. X ; Li, Y. L; Liu, H. B.; Guo, Y. B.; Li, Y. J.; Zhu, D. B. Chem Commun. 2010, 46, 3256. doi: 10.1039/b922733d

(3) Jia, Z. Y.; Li, Y. J.; Zuo, Z. C.; Liu, H. B.; Huang, C. S.; Li, Y. L. Acc. Chem. Res. 2017, 50, 2470. doi: 10.1021/acs.accounts.7b00205

(4) Xi, J. Y.; Nakamura, Y.; Zhao, T. Q.; Wang, D.; Shuai, Z. G. Acta Phys. -Chim. Sin. 2018, 34, 961. [奚晋扬, 中村悠马, 赵天琦, 王冬, 帅志刚. 物理化学学报, 2018, 34, 961.] doi: 10.3866/PKU.WHXB201802051

(5) Chen, X.; Zhang, S. L. Acta Phys. -Chim. Sin. 2018, 34, 1061. [陈熙, 张胜利. 物理化学学报, 2018, 34, 1061.] doi: 10.3866/PKU.WHXB201801311

(6) Zhou, J. Y.; Zhang, J.; Liu, Z. F. Acta Phys. -Chim. Sin. 2018, 34, 977. [周劲媛, 张锦, 刘忠范. 物理化学学报, 2018, 34, 977.] doi: 10.3866/PKU.WHXB201801243

(7) Li, Y. J.; Li, Y. L. Acta Phys. -Chim. Sin. 2018, 34, 992. [李勇军, 李 玉良. 物理化学学报, 2018, 34, 992.] doi: 10.3866/PKU.WHXB201801302

(8) Lee, J.; Li, Y.; Tang, J. N.; Cui, X. L. Acta Phys. -Chim. Sin. 2018, 34, 1080. [李乔丹, 李永, 唐佳宁, 崔晓莉. 物理化学学报, 2018, 34, 1080.] doi: 10.3866/PKU.WHXB201802262

(9) Lu, X. L.; Han, Y. Y.; Lu, T. B. Acta Phys. -Chim. Sin. 2018, 34, 1014. [卢秀利, 韩莹芗, 鲁统部. 物理化学学报, 2018, 34, 1014.] doi: 10.3866/PKU.WHXB201801171

(10) Zhao, Y. S.; Zhang, L. J.; Qi, J.; Jin, Q.; Lin, K. F.; Wang, D. Acta Phys. -Chim. Sin. 2018, 34, 1048. [赵亚松, 张丽娟, 齐健, 金泉, 林凯峰, 王丹. 物理化学学报, 2018, 34, 1048.] doi: 10.3866/PKU.WHXB201802281

(11) Huang, Z. J.; Yu, Z. N.; Li, Y.; Wang, J. Z. Acta Phys. -Chim. Sin. 2018, 34, 1088. [黄志娟, 喻志农, 李言, 王吉政. 物理化学学报, 2018, 34, 1088.] doi: 10.3866/PKU.WHXB201801251

(12) Shen, X. Y.; He, J. J.; Wang, N.; Huang, C. S. Acta Phys. -Chim. Sin 2018, 34, 1029. [神祥艳, 何建江, 王宁, 黄长水. 物理化学学报, 2018, 34, 1029.] doi: 10.3866/PKU.WHXB201801122

(13) Chen, Y. H.; Li, J. F.; Liu, H. B. Acta Phys. -Chim. Sin. 2018, 34, 1074. [陈彦焕, 李教富, 刘辉虎. 物理化学学报, 2018, 34, 1074.] doi: 10.3866/PKU.WHXB201801231 